\title{
La música en el desarrollo de la espiritualidad y la religiosidad. Una aproximación al Cristianismo y al Budismo
}

\author{
Ana María GuTIÉRREZ \\ Universidad de Córdoba \\ amagumaflauta@gmail.com
}

\section{RESUMEN}

La música puede afectar al individuo en todos sus niveles-físico, mental y espiritual-. El presente artículo se centra en el papel que ésta desempeña en el desarrollo de la vida espiritual y trascendental. Para ello, realizaremos un repaso histórico de su evolución estética y social, abordaremos dicho fenómeno a nivel fisiológico y presentaremos sus aplicaciones clínicas y sociales. Seguidamente y a modo de ejemplo de las concepciones de pensamiento occidental y oriental, trataremos la forma en que el cristianismo y el budismo conciben la música dentro de su doctrina. Finalizaremos con algunas reflexiones sobre el tema.

Palabras clave: Música, espiritualidad, religiosidad, Cristianismo, Budismo.

Music in the Development of Spirituality.

An approach to Christianity and Buddhism

\begin{abstract}
Music can affect the individual in all its physical, mental and spiritual levels. This article focuses on the role that it plays in the development of spiritual and transcendental life. To do this, we will make a historical review of its aesthetic and social development, will address this phenomenon physiologically and present their clinical and social applications. Then and as an example of the concepts of Western and Eastern thought, we shall try to describe how Christianity and Buddhism conceive music in its doctrine. We end with some thoughts on the subject.
\end{abstract}

Keywords: Music, spirituality, religiosity, Christianity, Buddhism.

SUMARIO: 1. Introducción. 2. Evolución histórica y estética. 3. Resurgimiento espiritual e influencia oriental. 4. Impacto cerebral y espiritual. 4.1. Música y frecuencias cerebrales en los procesos emocionales. 4.2. Ritmos binaurales. 5. Experiencia musical individual y colectiva. 6. Música y meditación: Mindfulness. 7. Aplicaciones sociales y clínicas. 8. Música y religión. 9. Conclusiones. 10. Bibliografía. 


\section{INTRODUCCIÓN}

La sociedad del siglo XXI podría entenderse como la de la «imagen» y la de la «apariencia». Los medios de comunicación nos desbordan con mensajes en los que el poseer bienes y contar con cierto prestigio social parecen los únicos medios para alcanzar la autorrealización y el reconocimiento personal. Este materialismo imperante crea falsas expectativas y una mentalidad dependiente de la realidad exterior, al inculcar que la felicidad y la paz son factores externos, cuando en realidad los llevamos incorporados desde el nacimiento dentro de nosotros.

Cuanto más «ruido» recibimos, más difícil se hace el proceso de encuentro personal y de desarrollo espiritual y, por eso, el primer paso para sentirse lleno parte de vaciarse de las necesidades y apegos del mundo exterior. En este sentido, existen concepciones religiosas que destacan la importancia de reencontrarse con uno mismo para poder alcanzar la plenitud. Muy convenientes resultan las palabras de Fray Luis de León al destacar las virtudes de aquellos sabios que, gracias a su «alejamiento» del mundanal ruido, consiguieron encontrar el silencio interior que les llevó a la sabiduría y a la trascendencia ${ }^{1}$ :

¡Qué descansada vida

la del que huye del mundanal ruido,

y sigue la escondida

senda por donde han ido

los pocos sabios que en el mundo han sido!

Llegar a dicho estado de trascendencia es posible y, de hecho, cada persona puede alcanzarlo por sí misma a través de un trabajo interno, muy ligado al desarrollo espiritual y favorecido en muchos casos por la religiosidad y la fe. Del mismo modo, conviene aclarar que el trabajo mental y el espiritual son dos aspectos bien diferenciados, aunque pueden ser complementarios. Así, podría decirse que la parte mental es aquella que implica todos los procesos cerebrales traducidos en términos de reacciones físicas ante estímulos determinados, mientras que lo espiritual se remonta a aquellos estados que se elevan de lo puramente físico y tangible. Así, si estableciéramos una escala que fuera de lo tangible a lo intangible y trascendental, podría establecerse lo físico como escalón más primario, lo mental como categoría intermedia entre lo físico y lo intangible y lo espiritual como lo más trascendental e incorpóreo, relacionándose con el enfoque más introspectivo y profundo del ser.

Llegados a este punto, resulta fundamental distinguir entre espiritualidad y religiosidad, ya que son dos conceptos que se prestan a equívoco, dado que la idea más extendida a nivel social es que no puede existir espiritualidad sin religiosidad. Sin embargo, se trata de dos términos bien diferenciados, aunque complementarios

1 Tierno 2005, 130. 
e interrelacionados en muchos casos. Así, se puede ser religioso pero carecer de espiritualidad, o ser espiritual pero no necesariamente religioso. En este artículo, se tratarán aspectos ligados a la religiosidad y otros a la espiritualidad, pero siempre partiendo de la entidad que cada concepto tiene por sí mismo de manera independiente.

No obstante y con el objetivo de aclarar los términos, entendemos espiritualidad como «aquello que posee espíritu» ${ }^{2}$, incluyendo la «parte inmaterial, intelectual o moral del hombre» ${ }^{3}$, así como otros aspectos como la búsqueda de sentido, de esperanza o de tener fe en uno mismo o en la divinidad ${ }^{4}$. De esa forma, las escuelas espirituales proponen metodologías diferentes para desarrollar la experiencia mística, sin ir por ello asociadas a un Dios 5 .

Por otra parte, la religiosidad se define como la práctica de la religión o «conjunto de creencias o dogmas acerca de la divinidad, de sentimientos de veneración y temor hacia ella, de normas morales para la conducta individual y social y de prácticas rituales, principalmente la oración y el sacrificio para darle culto» ${ }^{6}$.

Diferenciados ambos términos, destacaremos la función que la música tiene en ellos, ya que contribuye en gran medida al desarrollo espiritual y, en función ello, son numerosas las religiones que la incluyen dentro de su liturgia o como proceso místico de unión con Dios. En este caso, nos centraremos en dos de las religiones más conocidas e influyentes en la sociedad occidental del siglo XXI -cristianismo y budismo-. Utilizaremos sus doctrinas como ejemplos del pensamiento occidental y oriental.

\section{EVOLUCIÓN HISTÓRICA Y ESTÉTICA}

Los conceptos de espiritualidad y religiosidad han estado muy presentes a lo largo de las diferentes etapas que se han sucedido dentro de la historia de la música occidental. De hecho, ya desde la Antigua Grecia encontramos que estos tres términos -música, religión y espíritu, o magia en esta época- son intercambiables. Así, a la música se le atribuyen poderes sobrenaturales capaces de llevar a estados trascendentales de purificación mental y espiritual ${ }^{7}$, conectando con los dioses y con los seres de ultratumba a través de rituales cargados de simbolismo. Del mismo modo, la mitología griega considera a los dioses como los inventores de la música, siendo muchos de ellos instrumentistas y dando lugar a danzas y rituales en su honor -Apolo es asociado a la cítara y Dioniso al aulós, por ejemplo ${ }^{8}$.

\footnotetext{
2 Real Academia Española 2001.

3 Jiménez 2005, 92-101.

4 Rodríguez 2011, 205-213.

5 Yentzen 2004.

${ }^{6}$ Real Academia Española 2001.

${ }^{7}$ Remitimos en este punto a la diferenciación entre lo físico, mental y espiritual realizada en la introducción.

8 Molina 1998, 7-35
} 
No será menor la importancia de la música durante la época del Imperio Romano. Aquí destaca su nueva concepción, unida ahora a la teología, por parte de los Padres de la Iglesia -San Agustín y San Isidoro de Sevilla, entre otros ${ }^{9}-$, además de la sustitución de instrumentos griegos por romanos tras la conquista de Grecia -el aulós griego se sustituye por la tibia romana-.

Posteriormente, el declive romano lleva al avance del cristianismo como religión principal en el continente europeo, incorporándose la música a la liturgia, pero con cierto recelo respecto a la música instrumental, al haber estado asociada en épocas anteriores a espectáculos públicos y ritos que nada tenían que ver con el plano espiritual o moral. Por ello, el cristianismo empieza a forjar su propia liturgia bajo la base de cantos asociados a textos bíblicos como los salmos, con acompañamiento de instrumentos de cuerda.

La división de la zona occidental de Europa durante los siglos VII y VIII entre los lombardos, los francos y los godos, establece diferentes estilos musicales. Debemos mencionar la labor del papa Gregorio I en la conservación del patrimonio musical galo que comenzaría a conocerse como gregoriano, convirtiéndose en el germen de evolución de la música occidental.

En la Edad Media, el canto llano trasciende lo puramente melódico para convertirse en una oración en la que el texto determina todos los parámetros compositivos. Así, cada parte de la liturgia adopta sus propios textos, los oficios y la misa van evolucionando y surgen nuevas manifestaciones como los dramas litúrgicos, ligados a la representación teatral de textos del evangelio relacionados con festividades cristianas.

Por otra parte, aunque las melodías sacras sirven de base compositiva en etapas posteriores -Escuela de Notre Dame de los siglos XI y XII-, lo profano empieza a equipararse en importancia y abundancia a lo religioso y la Iglesia toma un punto de vista conservador y hermético, al rechazar aquellas melodías que enturbian el texto y no permiten al oyente escuchar la palabra de Dios ${ }^{10}$.

Este tema no quedará exento de polémica y el tema de la innovación y la tradición en la creación musical seguirá presente en siglos posteriores -siglos XIII y XIV, con la corriente del Ars Nova ${ }^{11}$, siglos XV y XVI con Tinctoris y la Reforma de Martín Lutero $^{12}$.

Ya durante el Barroco, encontramos ejemplos de repertorio religioso en compositores tan ilustres como J.S. Bach -La Pasión según san Mateo- y G.F. Haendel -el oratorio El Mesías-, por ejemplo. A pesar del laicismo que caracteriza estos siglos, los temas religiosos siguen presentes en el Clasicismo musical, como reflejan las producciones de F.J. Haydn -Misa de Mariazell y el oratorio La Creación-y W.A. Mozart -Misa de la Coronación KV. 317 y Requiem, completado por su alumno F.X. Süssmayr-.

\footnotetext{
${ }^{9}$ Quasten 1930; Gérold 1931; McKinnon 1987.

10 Grout y Palisca 2006, 38-116.

11 Fubini 2005, 115-125.

12 Gallico 1986, 57-60.
} 
El Romanticismo es la época de las emociones desatadas y, en este sentido, la música alcanza una dimensión trascendental relacionada con la religión, desde el punto de vista de que ésta también permite elevarse hacia esos estados. La música se convierte en un elemento espiritualizado que llevará a mediados del siglo XIX al debate sobre la reforma musical dentro de la Iglesia católica romana, posicionándose a favor del estilo a capella propio del canto gregoriano.

Por otra parte, en el siglo XIX, la filosofía de Nietzsche, que rompe con la moralidad, la religiosidad y la filosofía tradicional clásica, influye en compositores como Richard Strauss, con su poema sinfónico Así habló Zaratustra ${ }^{13}$. El ideal del «superhombre» creado por el filósofo alemán revoluciona el panorama europeo y supone la decadencia de la religiosidad y la espiritualidad, volviendo a resurgir de forma renovada en la postmodernidad de finales del siglo XIX y durante todo el siglo XX gracias a la influencia de las tradiciones y religiones orientales ${ }^{14}$.

\section{RESURGIMIENTO ESPIRITUAL E INFLUENCIA ORIENTAL}

Hales apunta que «el siglo XIX permite ver con mucha claridad el resurgimiento del misticismo» ${ }^{15}$. La crisis de la cultura occidental y el contacto iniciado con tradiciones orientales de países como China, India y Japón -sufismo, hinduismo, budismo y tradiciones chamánicas- provocan una atracción hacia nuevas formas de espiritualidad que tratan de recuperar el sentido trascendental de la vida. Respecto al acercamiento a la filosofía asiática, el pensador Alan Watts señala el valor de estas formas de vida, pues van más allá que otros cultos en los que el sentido de la existencia es Dios y no la propia persona.

En el siglo XX, el materialismo y la falsa creencia de alcanzar la autorrealización a través del bienestar económico empiezan a ser reemplazados por otras formas de pensamiento que rompen con todo lo anterior. Así, corrientes filosóficas como el ateísmo, el agnosticismo, el existencialismo, el nihilismo y el surrealismo tratan de marcar tendencias alejadas de antiguos patrones.

Tras la Segunda Guerra Mundial y especialmente a partir de los años sesenta, se crea en Estados Unidos una nueva mentalidad que propugna el resurgimiento espiritual. En este sentido, el pensador Alan Watts advierte en los años sesenta de los graves peligros que la civilización occidental corre si se limita tan solo a lo material y desecha la parte espiritual de cada ser. Esta nueva mentalidad se ve especialmente influenciada por el budismo zen y, posteriormente, por el sufismo y el hinduismo, corrientes que nutren de forma paralela a la psicología humanista americana. Este intento por crear nuevos estados de conciencia hace renacer el concepto de divinidad y la esperanza de que cada hombre sea capaz de alcanzar la iluminación. Resultado

13 Grout y Palisca 2006, 856-859.

14 Yentsen 2004.

15 Yentsen 2004. 
de todo ello será una nueva forma de vida basada en la capacidad para soñar y en la creencia en un orden superior que permite la creación de un mundo mejor a través de la autorrealización personal.

Finalmente, la convivencia y el contacto entre las tradiciones occidentales y orientales también supone un gran progreso en los países orientales, dando pie al surgimiento de grandes maestros espirituales que se introducen en el panorama occidental, tales como Ramakrishna, Rabindranath Tagore y Mahatma Gandhi, entre otros. Este intercambio de ideas en armonía lleva a la expansión mental y a la flexibilidad de pensamiento en un mundo hasta entonces dominado por una cultura capitalista estricta y hegemónica.

\section{IMPACTO CEREBRAL Y ESPIRITUAL}

Antes de pasar a tratar cómo la religión da cabida a la música dentro de sus prácticas y doctrinas, conviene analizar el papel que el fenómeno sonoro desempeña a nivel cerebral y espiritual, ya que son estos efectos los que hacen aflorar emociones intensas ligadas con la plenitud espiritual, además de favorecer la creación de estados catárticos y de trance asociados a los ritos de algunas tradiciones místicas.

\subsection{MÚSICA Y FRECUENCIAS CEREBRALES EN LOS PROCESOS EMOCIONALES}

No cabe duda de que la música es un potente agente de liberación emocional. Numerosos son los cambios que el fenómeno sonoro produce en la actividad cerebral, actuando en áreas tanto del hemisferio izquierdo -cerebro lógico, analítico, calculador, serial y especializado en el lenguaje-, como del derecho -cerebro emocional, intuitivo, abstracto, artístico y metafísico, asociado a la afectividad. Dentro del segundo, pueden establecerse, además, otros dos subgrupos, con un total de cuatro cuadrantes que forman la corteza cerebral.

Tanto la música como la búsqueda de la trascendencia a través de la religiosidad o de la vida espiritual se mueven en el ámbito del hemisferio derecho, por lo que pueden interactuar y reforzarse de forma mutua. Así, la música puede llevar a estados de trance y elevación gracias a la utilización de determinados elementos compositivos -armonía, melodía, ritmo, instrumentación, etc.-, así como evocar recuerdos y experiencias de alto contenido emocional y que contribuyen a estimular este estado de plenitud. Del mismo modo, tanto la música como el cerebro obedecen a unas frecuencias de vibración determinadas que producen ondas de mayor o menor frecuencia en función de su número por minuto. El cerebro funciona con energía bio-químicoeléctrica de baja potencia que permite procesar los estímulos y generar una respuesta. El proceso se completa cuando el tálamo y la glándula pineal reciben las cargas eléctricas enviadas por las neuronas cada 12,5 milisegundos, existiendo receptores elec- 
tromagnéticos que, según Devereux, permitirían sentir corrientes electromagnéticas de energía sutil procedentes del $\operatorname{cosmos}^{16}$. Este fenómeno permite al cerebro emitir y recibir información extrasensorial y romper con los conceptos de tiempo y espacio, al crear formas de pensamiento que se elevan por encima de lo puramente sensorial.

En cuanto a las ondas cerebrales, descubiertas por Berger en los años 20 del siglo XX, cada una de ellas se traduce en un estado físico-fisiológico-mental-comportamental, mediado por sustancias químicas y hormonas que se vierten al torrente sanguíneo y que interactúan entre si ${ }^{17}$.

Así, las ondas gamma -de 30 a $40 \mathrm{~Hz}-$ y las beta -de 14 a $30 \mathrm{~Hz}-$, forman parte del estado consciente del individuo y se dan durante la vigilia. Las primeras llevan a estados de histeria, pérdida de control, pánico, agresividad, huida y ansiedad desbordada y pueden ser producidas por ruidos fuertes, situaciones de máxima tensión o noticias traumáticas. Aquí se libera adrenalina, cortido-asteroides y STH u hormona somato-tropa. En el caso de las segundas, son propias del pensamiento cotidiano, la conversación, la atención externa, el razonamiento lógico y los estados de concentración regular. Liberan adrenalina moderada y generalizada.

El resto de ondas -alfa, theta y delta- responden a estados cerebrales inconscientes, por lo que resultan especialmente relevantes a la hora de resolver conflictos internos no procesados y de conectar con la parte más íntima del ser.

Así, las ondas alfa-de 7,5 a $13 \mathrm{~Hz}$ - resultan imprescindibles en los procesos espirituales y de contemplación, ya que conllevan reposo e introspección, atención hacia el propio pensamiento o hacia el aspecto más íntimo del ser, lucidez, creatividad, mayor capacidad de concentración y rendimiento, intuición, fluidez y autosugestión. Aquí se liberan endorfinas y catecolaminas, que pueden ser creadas artificialmente a través de psicofármacos y sustancias relajantes. La mejor forma de producirlas es a través de la relajación activa o pasiva, las actividades de ocio -especialmente las que requieren concentración-, los psicotrópicos, la oración, la meditación y el pensamiento en blanco. En este sentido, la música potencia en gran medida la generación de ondas alfa, ya que muchos instrumentos -voz, arpa, campanas, tenedores y cuencos tibetanos, gong y órgano, por ejemplo- se mueven en un espectro sonoro similar o muy parecido al de estas ${ }^{18}$. Además, el efecto de «trance» se multiplica si las melodías son monocordes -canto gregoriano, por ejemplo-, o de carácter reposado y repetitivo, si el tempo es lento y si se complementan con otros métodos de relajación, como el control de la respiración, la autosugestión, la visualización -de escenas naturales o mandalas- y los aromas relajantes de aceites naturales e incienso. Todo esto contribuye a alcanzar el estado de introspección necesario para llegar a la plenitud espiritual, desprovista de toda dependencia con la realidad exterior.

En el caso de las ondas theta-de 3,5 a 7,5 Hz-el cerebro se encuentra en un estado a medio camino entre la vigilia y el sueño gracias a la segregación de en-

\footnotetext{
16 Bluestone 2001,111.

17 Paymal 2014, 148-151.

18 Heather 2014, 28-29.
} 
dorfinas y catecolaminas -también presentes en las ondas alfa- en concentraciones superiores. Su similitud con las ondas anteriores se da asimismo en las actividades que propician su producción -meditación profunda, música relajante y armoniosa, yoga, visualizaciones, situaciones placenteras de gran calma y drogas psicotrópicas-, aunque el comportamiento es diferente. Así, mientras que con las ondas alfa se conseguía alcanzar un estado de descanso, las ondas theta van mucho más allá, asociándose con el estado de inspiración y llevando a imágenes, ensoñaciones, fantasías e incluso alucinaciones donde la mente se abstrae del mundo exterior y «vuela» por sí misma. La relajación física y mental es completa, siendo el estado característico de los momentos previos a caer dormidos y durante el sueño MOR -Movimiento Orbital Rápido-. Ésta es la frecuencia que emiten los discípulos zen, los monjes budistas y los religiosos y místicos cristianos cuando meditan. En este sentido, la música ayuda a profundizar el estado de relajación y catarsis asociado a las oraciones y mantras utilizados. Sin embargo, más que de música, hablaremos de frecuencias adaptadas mediante amplificaciones de dichas ondas, dado que, por no formar parte del espectro de audición humano, no son audibles, aunque sí perceptibles en el sistema límbico de forma inconsciente y subliminal.

Tanto las ondas alfa como las theta tienen importantes beneficios sobre el individuo. Así, potencian la concentración y el rendimiento, fomentan estados de tranquilidad y trascendencia, mejoran la creatividad, refuerzan el sistema inmunitario, aumentan la energía vital, la felicidad y la autoestima, mejoran la calidad de las relaciones sexuales, reordenan y reequilibran la mente y contribuyen a la sanación holística. Esto último es posible porque, a esos niveles, los dos hemisferios cerebrales trabajan de manera más integrada y unificada, sumando las potencialidades del pensamiento analítico propio del hemisferio izquierdo con la creatividad y capacidad características del hemisferio derecho. De esa manera, el cerebro crea un estado sinérgico en el que utiliza todas sus posibilidades, consiguiendo resultados mucho mayores de los que se conseguirían si cada lóbulo cerebral trabajara de manera independiente.

Respecto a las ondas delta-de 0,5 a $3,5 \mathrm{~Hz}-$ son las más desconocidas y se corresponden con el sueño profundo, donde la relajación es máxima, con estados de reacondicionamiento físico y reestructuración mental. Este estado se asocia a los viajes astrales y a los estados hipnóticos profundos.

Por otra parte y como habíamos mencionado anteriormente, la música, a su vez, es capaz de provocar fuertes emociones y cada una de ellas responde a un nivel determinado de frecuencia vibratoria. Se ha demostrado que existen dos emociones principales -amor y miedo-, incluyéndose en cada una emociones secundarias y derivadas de estos estados principales -paz y alegría en el primer caso, por ejemplo, y rabia y frustración en el segundo-. En la estructura del ADN existen 64 códigos posibles de aminoácidos compuestos por carbono, oxígeno, hidrógeno y nitrógeno. A pesar de esto, sólo 20 de ellos se encuentran activos en cada momento y, por eso, existe un «interruptor» de emociones que se encarga de activar y desactivar cada código según la emoción predominante. Los sentimientos de miedo y sus derivados -ira, ansiedad, abandono, vergüenza, culpa, tristeza y envidia- tocan menos puntos de la cadena de 
ADN y, en ese sentido, describen una onda más larga, mientras que el amor y sus emociones secundarias -satisfacción, agradecimiento, esperanza, expansión, alegría, amor, fluidez, confianza, armonía y elevación-, al tocar más puntos de la cadena, dibujan una trayectoria más alta ${ }^{19}$.

\subsection{RITMOS BINAURALES}

En cuanto a la forma de potenciar la producción de las ondas cerebrales descritas en el punto anterior, existen métodos de estimulación, tanto unilateral como bilateral, en los que se utilizan sonidos de frecuencias similares a las de cada tipo de onda. Es aquí donde entran los denominados ritmos binaurales, descubiertos en 1839 por H.W. Dove y basados en la utilización de sonidos de frecuencia similar a los de las ondas cerebrales que se pretende crear, con el objetivo de sincronizar ambas -las cerebrales y las escuchadas- y, en consecuencia, provocar determinados estados de conciencia ${ }^{20}$.

En este terreno, existen numerosas investigaciones que confirman tales efectos. Hiew (1995) demuestra cómo los rangos delta y theta inducen estados de relajación, meditación y creatividad. Morris (1990) trata la integración de lo sensorial y Wilson (1990) y Rhodes (1996) la inclusión de estos sonidos para mejorar el sueño. Waldkoetter (1997) prueba la disminución de los síntomas de depresión en alcohólicos a través de ritmos binaurales de baja frecuencia, complementados con terapia cognoscitiva. Foster (1990) se centra en las frecuencias alfa -incrementan las ondas cerebrales-, mientras que Monroe (1985), Lane (1998), Kennerly (1994) y Guilfoyle (1996) lo hacen en las beta -favorecen la concentración, la atención, la vigilancia y la capacidad memorística ${ }^{21}$.

Por otra parte, los ritmos binaurales ${ }^{22}$-producidos por la estimulación simultánea de los dos oídos-crean ritmos neurológicos ultradianos que producen cambios en los estados de conciencia y que podrían alterar la eficacia de los ritmos aurales ${ }^{23}$-fruto de la estimulación de un solo oído-. La adición de ruido blanco ${ }^{24}$-sonido complejo de espectro continuo y uniforme e igual energía en cada banda de frecuencia absoluta continua, producido por el movimiento desordenado de moléculas por agitación térmica o de los electrones- rosa $^{25}$-sonido complejo de densidad espectral inversa-

\footnotetext{
19 No debemos confundir esta longitud de onda con la longitud de onda cerebral. El miedo, por ejemplo, al contener ondas gamma describe una onda cerebral rápida, pero un dibujo lento respecto a la actuación en los códigos de ADN -al tocar menos códigos, la onda es más larga-. Por ello, resulta fundamental puntualizar que ambas cadenas son independientes e inversas.

20 Oster 1973, 94-102.

21 González 2013, 41-43.

22 Piéron 1993, 74.

23 Piéron 1993, 62.

24 Piéron 1993, 469.

25 Piéron 1993, 470.
} 
mente proporcional a la frecuencia, con un espectro continuo de igual energía en cada banda de amplitud en valores relativos- de fondo aumenta la percepción de los ritmos aurales, al igual que determinados ejercicios de entonación y respiración, el entrenamiento y la retroalimentación producida por la interrupción del estado homeostático de quien resiste a los efectos de dichos ritmos ${ }^{26}$.

No obstante y dada su eficacia en general, los ritmos aurales siguen siendo una herramienta utilizada para inducir determinados estados anímicos y mentales a través del sonido, muchos de ellos con fines terapéuticos.

\section{EXPERIENCIA MUSICAL INDIVIDUAL Y COLECTIVA}

La música está presente en numerosos eventos cotidianos y forma parte integrante del ser. Beethoven apuntaba que «la música es la mediadora entre la vida espiritual y la de los sentidos» ${ }^{27}$, destacando el papel de lo sensorial -el aparato auditivo- y lo introspectivo y trascendental -considerado por muchos como «alma»-.

Si bien es cierto que la música constituye un fenómeno sensorial, también lo es que puede tener un efecto trascendental en el individuo. Además de poder actuar como una herramienta terapéutica -música como medio-, también contribuye en gran medida al simple deleite y al hedonismo propio de quien escucha por placer -música como fin-. En este sentido, cada persona experimenta una relación propia e íntima con el fenómeno sonoro, ya que no todas las melodías provocan los mismos efectos en todos los individuos. De hecho, la mayor o menor capacidad de la música para suscitar respuestas viene determinada en gran medida por la experiencia personal que se haya tenido con dicha melodía o con otras similares. Se podría decir que cada persona tiene una identidad sonora que la caracteriza - principio ISO de Benenzon ${ }^{28}$, mediada por otros parámetros como la capacidad de cada sujeto para decodificar el mensaje musical ${ }^{29}$, sus preferencias y sus diferencias individuales y culturales.

Asimismo, el proceso de escucha musical está marcado por cinco factores: búsqueda del fenómeno sonoro, evocación de una o varias emociones, regulación de la disposición anímica, recompensa en el plano social y motor sensorial. Todo ello provoca cambios en numerosos ámbitos del sujeto.

En el plano fisiológico, las técnicas de neuroimagen muestran la activación de áreas cerebrales implicadas en la emoción y de redes asociadas a los mecanismos de recompensa y placer, incluyendo además al sistema mesolímbico dopaminérgico. También, la música permite sincronizar el ritmo cardíaco o de cualquier otra parte del cuerpo con el ritmo del fragmento sonoro, lo que consigue una compleja coordinación en el cerebro somatosensorio-motor cortical y subcortical. En cuanto a las hor-

\footnotetext{
26 Shannahoff-Khalsa 1991, 225-251.

27 Quesada 2011.

28 Camacho 2006, 155-188.

29 Gabrielsson y Juslin 2003, 91-110.
} 
monas, la música incrementa la segregación de estimulantes inmunológicos y reduce las cantidades de cortisol y otras sustancias presentes en los procesos de estrés ${ }^{30}$. Así, estudios con imágenes por resonancia magnética muestran una desactivación de la amígdala -responsable de sentimientos de miedo y presente en procesos de estrésdurante la escucha de melodías agradables, produciéndose una mediación entre las zonas cerebrales asociadas a mecanismos de recompensa y aquellas encargadas de procesar y reducir los estados afectivos negativos. Del mismo modo, algunos autores plantean una similitud entre la selección sexual realizada por los pájaros según su canto y la realizada por las personas, por lo que la música podría actuar como reforzador de la recompensa sexual ${ }^{31}$.

Por lo que se refiere a las emociones, la música facilita la liberación y expresión de los sentimientos, permite el placer, induce a la relajación y disminuye el estrés -sobre todo cuando las actividades cotidianas se acompañan de música-. Esto explica su uso en rituales y en fenómenos artísticos como el cine, donde las emociones se desatan en gran medida por la música que acompaña a la imagen.

Por último, la música contribuye de forma considerable al contacto y a la adaptación al medio social, ya que mejora las relaciones interpersonales. Así, está presente en numerosos eventos sociales, define identidades concretas al existir estilos musicales ligados a formas de vida muy específicas, mejora los lazos afectivos y transmite valores, entre otros. Del mismo modo, el compartir la experiencia musical y coincidir varios individuos en sus preferencias sonoras puede incrementar el atractivo grupal y la cohesión a él.

Todos estos aspectos ligados al nivel trascendental de la música permiten que, al mejorar un sujeto a nivel individual, se produzca en consecuencia una mejora social, dado que también forma parte de tal colectivo. Por ello, la espiritualidad puede ser compartida en grupos de encuentro que se reúnen para poner en común sus experiencias y donde la música adquiere un importante papel al desatar los sentimientos más íntimos del ser.

\section{MÚSICA Y MEDITACIÓN: MINDFULNESS}

Si bien la meditación constituía en décadas pasadas una práctica poco conocida y con un reducido número de asiduos, en los últimos años ha experimentado un gran auge $^{32}$. Así, ha llegado a extenderse en la sociedad como una de las formas más efectivas en la lucha contra el estrés característico del siglo XXI y en la búsqueda de la trascendencia y la paz interior.

La meditación se entiende como el conjunto de prácticas de trabajo y entrenamiento de la atención y la conciencia, del control voluntario, del bienestar mental y

\footnotetext{
30 Heather 2014, 28-29.

31 Mas, Marco, Lorenzo, Zatorre y Rodríguez 2013, 118-138.

32 Davis y Hayes 2001, 198-208.
} 
del desarrollo de otras capacidades específicas -calma, quietud, claridad y concentración ${ }^{33}$-; no ha de confundirse con la relajación, ya que en la meditación se dan mayores niveles de atención y equilibrio entre los estados de activación y desactivación -aunque se esté en calma, la mente está alerta y concentrada-. Se trata, pues, de regular el cuerpo y la mente, previniendo tanto el exceso de activación como el de relajación.

Por otra parte, dentro de las prácticas meditativas, existe una más concreta, llamada mindfulness, sinónimo de Vipassana, una forma de meditación derivada del budismo «Theravada» y cuyo objetivo principal es el desarrollo de la conciencia ${ }^{34}$.

Así, la palabra mindfulness es una traducción de la palabra sati o «toma de conciencia». Por ello, también se refiere a un estado mental de plena conciencia y atención, marcado por el momento y desprendido de toda clase de juicio. Aquí, el proceso de introspección realizado por cada sujeto implica la comprensión de sus propios sentimientos, deseos y pensamientos, enfatizando el factor subjetivo y temporal y permitiendo desarrollar la fluidez y flexibilidad cognitiva.

Existen diferentes prácticas que contribuyen a la experiencia que llamamos mindfulness: práctica de yoga, tai chi, qigong y otras técnicas orientales y de relajación. Una de las que más contribuyen a dicho estado mental es la escucha de determinados tipos de música. En este sentido, destaca el experimento de la «Cuna Sónica»-Sonic $\mathrm{Cradle}^{35}$-. En él, los sujetos son suspendidos dentro de una cámara de sonido oscura en una especie de cuna colgante durante quince minutos, mientras escuchan música controlada digitalmente mediante su propia respiración. Todo ello lleva a un estado meditativo y de conciencia plena - mindfulness - en el que la mente se deja llevar por la música, abstrayéndose del resto del entorno y centrándose plenamente en la experiencia sonora. Los resultados arrojados por este estudio resaltan los numerosos beneficios que la música provoca en los procesos de meditación profunda. Entre ellos están: incremento de la autoestima y la autoconfianza, mejora de la atención, regulación de los estados emocionales, procesamiento de experiencias personales materializadas en imágenes mentales, fluidez, sentimiento de trascendencia, paz interior, evocación, claridad y lucidez, sensación de vacío, pensamiento positivo libre de preocupaciones y estado contemplativo carente de juicio.

Por otra parte, la meditación profunda a través del mindfulness ayuda a disminuir los pensamientos negativos y las quejas asociadas a ellos. Esto resulta de especial importancia en procesos de resiliencia donde se pretende crear cambios en la tendencia de pensamiento y, en consecuencia, en el comportamiento. Está demostrado que tras ocho semanas de práctica ya se observan alteraciones en la forma de procesamiento emocional del cerebro ${ }^{36}$. Esta «regulación de las emociones conscientes» contribuye a saber gestionarlas de una forma eficaz independientemente del entorno que rodee al

\footnotetext{
33 Walsh y Shapiro 2006, 227-239.

34 Guaratana 2002, ver Davis y Hayes 2001, 199.

35 Vidyarthi y Riecke 2014, 674-688.

36 Williams 2010, 1-7.
} 
sujeto, desarrollándose así el autocontrol ${ }^{37}$. En este sentido, la neuroplasticidad cerebral, que permite el modelaje y modificación de su estructura gracias a nuevos aprendizajes y experiencias, se ve muy favorecida, produciéndose diversos cambios. Entre éstos, destacan: engrosamiento del tronco cerebral ligado al pensamiento positivo y a las emociones ${ }^{38}$ y de las regiones relacionadas con la atención y el procesamiento sensorial, aumento de la concentración de materia gris, incremento de la velocidad de procesamiento de la información y reducción del esfuerzo y de los pensamientos no relacionados en la ejecución de tareas ${ }^{39}$.

Por último, también se distinguen beneficios de carácter inter- e intrapersonal. Así, en el primer caso, las personas que practican mindfulness presentan un menor nivel de estrés emocional en sus relaciones con otros sujetos y una menor ansiedad y enfado en situaciones de conflicto. De aquí se deriva una correlación inversa en la que los sujetos más entrenados en este estado de conciencia presentan un menor nivel de contagio de angustia social y una mayor conciencia de la situación.

En el segundo caso, las áreas cerebrales afectadas por el mindfulness -área del lóbulo prefrontal medio- provocan un aumento de los niveles de moralidad, intuición, autopercepción y control del miedo y de la ansiedad. Asimismo, se detecta una mejora en los niveles de empatía y autocompasión, factores esenciales en el proceso de bienestar personal y social.

\section{APLICACIONES SOCIALES Y CLÍNICAS}

Los beneficios de escuchar música y de llevar una vida espiritual son tales que ambos fenómenos son utilizados de forma terapéutica en la sanación de diversas enfermedades, tanto físicas como psíquicas. A continuación, hacemos un repaso de algunas de las patologías más destacadas en las que la música y la trascendencia ocupan un lugar importante dentro del proceso terapéutico:

a) Patologías físicas. Las ondas sonoras son utilizadas para destruir las piedras en el riñón y los cálculos biliares, mientras que los ultrasonidos eliminan las células cancerosas y los tumores. Esto es así porque las células sanas disfrutan con la vibración del sonido, mientras que las cancerosas son destruidas por él. Del mismo modo, la música acelera la sanación celular, reduciendo el dolor y produciendo diferentes efectos en el organismo, en función de los ritmos, los intervalos y las melodías utilizadas. Así, la música con muchos armónicos -canto gregoriano y música india, por ejemplo-cambia las estructuras cerebrales, estructurándolas y llevándolas a estados más equilibrados. Además, existen determinados instrumentos, como el arpa, que ya se están utilizando en los hospitales para combatir el infarto de miocardio y reducir

\footnotetext{
37 Chambers, Gullone y Allen 2009, 560-572.

38 Vestergaard-Poulsen, van Beek, Skewes, Bjarkam, Stubberup, Bertelsen y Roepstorff 2009, 170-174.

39 Davis y Hayes 2011, 198-208.
} 
la presión arterial. La voz de la madre al entonar una nana es otro ejemplo de cómo el canto reposado puede ayudar a tranquilizar al bebé en momentos de estrés.

b) Enfermedades terminales. En este tipo de patologías, la angustia de ver la muerte como algo muy próximo, lleva al paciente a desarrollar fuertes conflictos internos y procesos de elevado estrés. A nivel trascendental, la calma interna que la meditación y las prácticas espirituales -repetición de mantras, oraciones, elevación a través de la música- aportan contribuye en gran medida a calmar y equilibrar cuerpo, mente y espíritu ${ }^{40}$ a todos los niveles ${ }^{41}$. Por otra parte, refuerza los lazos del paciente con el terapeuta y la familia, contribuyendo a expresar emociones profundas ${ }^{42} \mathrm{y}$ creando un vínculo más humano que desarrolla en el paciente el agradecimiento y la paz interna que necesita para marcharse en paz ${ }^{43}$.

c) Abuso de sustancias. La espiritualidad y religiosidad actúan como elementos protectores ante el abuso de sustancias, ya que el vacío que el individuo siente y que le lleva a consumir puede ser llenado gracias a una figura trascendental como puede ser Dios. Hay estudios sobre la importancia del factor espiritualidad/religiosidad en tratamientos de drogodependencia y de alcoholismo (Desmond y Maddox 1981), contribuyendo además al desarrollo de la fuerza de voluntad y el autocontrol necesarios para prevenir las posibles recaídas y garantizar la eficacia de la terapia (Montgomery, Miller y Tonigan 1995) ${ }^{44}$.

d) Depresión mayor y ansiedad. Se ha demostrado la eficacia de la fe y la práctica religiosa -independientemente del tipo de religión profesada- en la reducción acelerada de los síntomas depresivos -apatía, baja autoestima, desconexión social y desesperanza, entre otros-. Lo mismo ocurre en personas con altos índices de ansiedad, como enfermos de cáncer y del corazón, pacientes en recuperación postoperatoria e individuos afectados por una experiencia traumática. Además, la meditación zen ayuda a disminuir e incluso eliminar por completo los síntomas que determinadas fobias y trastornos, como el pánico escénico, provocan ${ }^{45}$.

e) Psicosis y suicidio. Las dificultades de adaptación social que la esquizofrenia llega a provocar en el individuo que la padece, llevan en numerosos casos a desarrollar pensamientos suicidas. Aquí, las prácticas espirituales permiten reforzar el proceso de construcción del «yo» y trabajar los problemas de inadaptación social. En el caso del suicidio, aunque la charla con familiares y amigos pueda aliviar a corto plazo, está demostrado que no es suficiente para prevenirlo, cosa que sí ocurre con la práctica religiosa. Así, el riesgo de suici-

\footnotetext{
${ }^{40}$ Remitimos nuevamente a la diferenciación entre lo físico, mental y espiritual realizada en la introducción.

${ }^{41}$ Heather 2014, 28-29.

${ }^{42}$ McIntyre 2009, 260-268.

${ }^{43}$ Hartley 2001, 135-141.

${ }^{44}$ Rodríguez 2011, 205-213.

${ }^{45}$ Lin, Chang, Zemon y Midlasrky 2008, 139-155.
} 
dio se multiplica por cuatro entre aquellos que no trabajan la espiritualidad o la religiosidad en alguna de sus formas.

f) Procesos de convivencia y resiliencia social. La música mejora los procesos de comunicación humana y convivencia, gracias a su marcado carácter participativo e inclusivo y a la posibilidad de expresar sentimientos que difícilmente podrían manifestarse con palabras. El bienestar provocado por la experiencia espiritual favorece la integración social en procesos de resiliencia, ya que ayuda a saber gestionar los recursos del entorno y las propias emociones para obtener una experiencia positiva y reforzadora, que contribuya a desarrollar las fortalezas humanas ${ }^{46}$. Así, los adolescentes con altos niveles de espiritualidad desarrollan comportamientos de menor riesgo social que aquellos que no tienen este hábito ${ }^{47}$. No obstante, existe cierta discrepancia sobre la correlación entre espiritualidad/religiosidad y resiliencia, pues los resultados de los estudios realizados no son del todo concluyentes.

\section{MÚSICA Y RELIGIÓN}

La música forma parte de la liturgia y de los rituales de numerosas religiones y corrientes espirituales. Dada la imposibilidad de analizar cada una de ellas, nos centraremos en dos de las más conocidas en la sociedad occidental del siglo XXI, como son el cristianismo y el budismo.

Cristianismo. A lo largo de su historia, el Cristianismo evoluciona y se va desgajando en numerosas corrientes, de las cuales la católica -la originaria Iglesia que Jesús «edifica» sobre Pedro- es las más conocida y extendida. Del mismo modo, también evoluciona la concepción musical, tanto en el plano compositivo como en su concepción social.

Así, San Agustín -ss. IV y V- destaca el poder de la música para modular el ánimo y despertar estados de placer y éxtasis. Ejemplo de ello es el apunte realizado por dicho autor al señalar el peligro del melisma realizado en uno de los «jubilus» del Aleluya, ya que la belleza de la melodía puede desviar la atención desde la palabra de Dios a lo puramente musical. Por ello, rechaza la música virtuosa, tachándola incluso de pecaminosa. No obstante, no anula el resto de manifestaciones musicales, a las que considera una forma de elevación, meditación, contemplación, adoración y oración a Dios - «quien canta bien, reza dos veces» ${ }^{48}$.

Del mismo modo, la música se convierte en un medio de proclamación de la palabra de Dios. Calvino ${ }^{49}$ cree que la música ha sido particularmente creada para «proclamar la alabanza de Dios», sirviendo de instrumento para la congregación de fieles.

\footnotetext{
46 Smith, Webber y DeFrain 2013, 1-16.

${ }^{47}$ Cotton, Larkin, Hoopes, Cromer, y Rosenthal 2005, 529.

48 Wren 2000, 1.

49 Calvin 1960, 894.
} 
Asimismo, los instrumentos musicales adquieren connotaciones morales y simbólicas que llevan al polémico tema de decidir cuáles han de incluirse en la liturgia y cuáles no. Y a esto se suma la discordia sobre el hecho de introducir o no la música dentro del servicio religioso. Algunos reformadores del siglo XVI, como Ulrich Zwingli, intentan eliminarla al considerar que el sonido de la melodía impide escuchar la palabra de Dios. Tras el Concilio Vaticano II de 1959, esta cuestión queda resuelta, de modo que las formas más tradicionales se ligan con el cristianismo católico y las más contemporáneas -dodecafonismo, aleatoriedad y técnicas interpretativas como el uso de clusters- con el protestantismo ${ }^{50}$.

Por otra parte, la música favorece los lazos y el sentimiento de comunidad religiosa, utilizándose coros de repertorio sacro o cantos colectivos interpretados por los fieles durante la liturgia. Además y como se destaca, la belleza del fenómeno musical se relaciona con la grandiosidad de todo lo creado por Dios y, por ello, ayuda a expresar la gratitud hacia el Creador y el sentimiento de pertenecer a un universo único, fruto del amor que Dios siente por el hombre. De hecho, para Lutero -siglo XVI-, la música es la más hermosa de todas las artes y la única que permite convertir a los hombres en mejores personas tan solo con escucharla. Con ese fin moralizador y social, ya en el siglo XX, el místico cristiano y monje trapense Thomas Merton persigue la solidaridad inspirada en la palabra de Dios, llevando a cabo una intensa labor en el barrio estadounidense de Harlem y luchando contra la discriminación del colectivo negro ${ }^{51}$.

Por otra, además de la música, el cristianismo destaca el papel del silencio en el proceso de adoración y contemplación. Benedicto XVI lo considera como una forma de canto que llama a otros cantos y sonidos del universo, llegando a crear una melodía audible, en el sentido de que el silencio puede llevar al individuo a estados de conexión y fusión con todo lo que le rodea, como si se tratase de una única música: la música de Dios ${ }^{52}$.

Como vemos, a pesar de las distintas concepciones que el cristianismo ha adoptado en la actualidad, todas coinciden en que la música puede tener un papel decisivo en el encuentro con Dios y en el servicio litúrgico y de amor al prójimo.

Budismo. Aunque sea una religión, el hecho de no proceder de una revelación divina -como el Cristianismo, el Judaísmo o el Islam, por ejemplo- sitúa al budismo en un camino intermedio entre doctrina religiosa y filosofía vital. De hecho, hay quien lo considera una forma de vida en la que la experiencia y la búsqueda de sentido se convierten en los principales objetivos para encontrar la felicidad. Así, se parte del hecho de sentirse un ser completo, iniciándose de ese modo un proceso de búsqueda individual y, posteriormente grupal, en el que el desprendimiento y la falta de condicionamiento hacia lo externo permiten la libertad y la unión con lo Absoluto.

\footnotetext{
50 Westermeyer 2013, 567-583.

51 Yentsen 2004.

52 Ratzinger 1996, 137.
} 
Etimológicamente, la palabra Budismo es una occidentalización del término en sánscrito Buddhadharma, constituido por las partículas Buddha, que quiere decir «El Despierto» y Dharma, «asunto, cosa, fenómeno». La traducción de la palabra al completo significa, por tanto, «El asunto del despertar», y ese despertar ha de producirse a todos los niveles del $\operatorname{ser}^{53}$.

Del mismo modo, sus prácticas espirituales inciden en gran medida en el plano mental y, en esta parcela, la música puede desempeñar un destacado papel. La utilización de instrumentos ricos en armónicos -cuencos tibetanos, gong, campanas-en las meditaciones facilitan la sincronización cerebral para conseguir estados de profunda introspección necesarios para alcanzar la iluminación o Nirvana. La concepción de la mente en el budismo gira en torno a las ideas de trascendencia -va más allá de la realidad existente-, conciencia pura -la claridad mental expande sus potencialidades hacia planos insospechados- e infinitud -la mente no tiene límites-. Una vez se desarrollan estas tres, las dimensiones de tiempo y espacio parecen difuminarse al alcanzar la paz interna que libera la auténtica esencia del «yo».

Por otra parte, el budismo se plantea como una alternativa para alejarse del sufrimiento, hecho que podría explicar -entre otros muchos- el éxito experimentado en la sociedad occidental a partir del siglo XIX ${ }^{54}$. Su proceso de búsqueda interna puede ser la cura frente a la ignorancia, la aversión, las crisis personales, las frustraciones y el apego a lo externo. Así, los miedos, las preocupaciones y todas aquellas inseguridades que salpican la vida cotidiana, desaparecen para dar pie al verdadero ser, despertando además sentimientos de compasión y empatía hacia el sufrimiento ajeno.

En definitiva, el budismo puede considerarse como una doctrina multidisciplinar que engloba religión -se venera la figura del Buddha aunque no sea un Dios-, filosofía - lleva a una forma de pensamiento que constituye un estilo de vida-, ciencia -plantea hipótesis que han de verificarse a través de la propia experiencia vital-y psicología -ayuda a la comprensión de la mente humana y a la búsqueda de la felicidad-. Por todo ello, también se entiende como una forma de terapia individualizada que tiene en cuenta las propias individualidades en las necesidades y en las capacidades y en la que lo principal no es «creer», sino «saber», pudiendo incluso apoyar a otras religiones, a las que consideraría como otras opciones de iluminación personal.

\section{CONCLUSIONES}

Como hemos visto, la música forma parte de la vida espiritual, no sólo por estar presente en rituales y liturgias, sino porque permite alcanzar lo trascendental con el simple hecho de escucharla, gracias a la combinación de sus diferentes elementos constitutivos -ritmo, melodía, armonía- y a las profundas emociones evocadas a través de ellos. Si bien hemos visto las numerosas ventajas que la vida espiritual

\footnotetext{
53 Bustamante 2004.

54 Yentzen 2004.
} 
ofrece, mayores son cuando incluyen la música en sus prácticas, sumándose así los beneficios individuales de cada una más los que se producen en conjunto. Vemos, por ello, que pueden ser prácticas complementarias entre las que se establece una clara simbiosis y una relación sinérgica.

Por otra parte, las posibilidades de la música y de la vida espiritual resultan especialmente adecuadas en procesos de resiliencia en los que el individuo intenta salir de una realidad traumática. Gracias a los altos índices de introspección alcanzados mediante la escucha activa y la práctica espiritual, el sujeto puede llegar a comprender que la verdadera felicidad no parte de la realidad exterior, sino del propio ser, encontrando la fortaleza necesaria para hacer frente a la adversidad. Este aspecto contribuye a la sanación holística a todos los niveles -físico, psíquico y espiritual ${ }^{55}$.

Finalmente, conviene recordar que si la música puede llevar al individuo a convertirse en un ser mejor, también puede aplicarse al ámbito social para conseguir el bienestar del grupo, pudiendo aplicarse con fines éticos y sociales para favorecer el apoyo comunitario, los lazos familiares e interpersonales y mejorar la formación emocional y cultural.

\section{BIBLIOGRAFÍA}

J. Bluestone, Return of the Children of Light, Incan and Mayan Prophecies for a New World, Bear \& Company, New Cork, 2001.

J.J. Bustamante, «El despertar y la felicidad en el budismo», http://polis.revues.org/5959 [acceso: 12.11.2014]

J. Calvin, Institutes of the Christian religion, Philadelphia, 1960.

P. Camacho, «Musicoterapia: culto al cuerpo y la mente», Envejecimiento activo, envejecimiento en positivo (2006) 155-188.

R. Chambers, E. Gullone, N.B. y Allen, «Mindful emotion regulation: An integrative review», Clinical psychology review 29 (2009) doi: 10.1016/j.cpr.2009.06.005

S. Cotton, E. Larkin, A. Hoopes, B.A. Cromer y S.L. Rosenthal, «The impact of adolescent spirituality on depressive symptoms and health risk behaviours», Journal of adolescent health 36 (2005) doi 10.1016/j.jadohealth.2004.07.017

D.M. Davis, y J.A. Hayes, «What are the benefits of Mindfulness? A practice review of psychotherapy-related research», Psychotherapy 48 [2] (2011) doi: 10.1037/a0022062

D.P. Desmond, y J.F. Maddox, «Religious programs and careers of chronic heroin users», American journal of drug and alcohol abuse 8 [1] (1981) 71-83.

D. S. Foster, «EEG and subjective correlates of alfa frequency binaural beat stimulation combined with alfa biofeedback», Hemi-Sync Journal, 8 [2] (1990) 1-2.

E. Fubini, La estética musical desde la Antigüedad hasta el siglo XX, Madrid, 2005.

${ }^{55}$ Ver diferenciación entre lo físico, mental y espiritual realizada en la introducción. 
A. Gabrielsson, y P.N. Juslin, Emotional expression in music, Nueva York, 2003.

C. Gallico, La época del Humanismo y Renacimiento (Vol. 4), Madrid, 1986.

T. Gérold, Les pères de l'église et la musique, Strasbourg, 1931 (reimpr. Ginebra, 1973).

P.M. González, Influencia de la estimulación sonora binaural en la generación de ondas cerebrales. Estudio encefalográfico, Madrid, 2013.

D.J. Grout, y C.V. Palisca, Historia de la música occidental 1, (ed. ampliada), Madrid, 2006.

H. Gunaratana, Mindfulness in plain English, Wisdom publications, New York, 2002.

G. Guilfoyle, y D. Carbone, The facilitation of attention utilizing therapeutic Sounds, New York State Association of Day Service Providers, 1996.

N.A. Hartley, «On a personal note: a music therapist's reflections on working with those who are living with a terminal illness»», Journal of Palliative Care 17 [3] (2001) 135-141.

S. Heather, «Sound», Psychic news (2014) 28-29.

C. Hiew, «Hemi-Sync into creativity», Hemi-Sync Journal 13 [1] (1995) 3-5.

J.P. Jiménez, «La espiritualidad, dimensión olvidada de la medicina», Gaceta Universitaria 1 (2005) 92-101.

R.C. Kennerly, An empirical investigation into the effect of beta frequency binaural beat audio signals on four measures of human memory, Department of Psychology, West Georgia College, Carrolton, Georgia, 1994.

J.D. Lane, S.J. Kasian, J.E. Owens, y G.R. Marsh, «Binaural Auditory Beats Affect Vigilance Performance and Mood», Behavioural Physiology 63 [2] (1998) 249-252.

P. Lin, J. Chang, V. Zemon y E. Midlasrky, «Silent illumination: a study on Chan (Zen) meditation, anxiety, and musical performance quality», Psychology of music 36 [2] (2008) doi 10.1177/0305735607080840

E. Mas-Herrero, J. Marco-Pallares, U. Lorenzo-Seva, R.J. Zatorre y A. Rodríguez-Fornells, «Individual differences in musical reward experiences», Music Perception 31 [2] (2013) doi: 10.1525/MP.2013.31.2.118.

J. McIntyre, «Interactive Family Music Therapy: Untangling the system», The Australian and New Zealand journal of family therapy 30 [4] (2009) doi: 10.1375/anft.30.4.260

J. McKinnon, Music in Early Christian Literature (antología de textos), Cambridge University Press, 1987, (reimpr. 1993).

F. Molina, Francisco, «Quinteto para dioses músicos en la mitología griega», Estudios Clási$\cos 40$ [113] (1998) 7-35.

R.A. Monroe, Far Journeys, New York: Doubleday, 1985.

H.A. Montgomery, W.R. Miller, y J.S. Tonigan, «Does alcoholics anonymous involvement predict treatment outcome?» Journal of substance abuse treatment 12 [4] (1995) 241-246 doi: 10.1016/0740-5472(95)00018-Z

S. Morris, «Emi-Sync and the facilitation of sensory integration», Hemi-Sync Journal 8 [4] (1990) 5-6.

G. Oster, «Auditory beats in the brain», Scientific American 229 [4] (1973) 94-102.

N. Paymal, Pedagooogia 3000. Una pedagogía para el tercer milenio 1, La Paz, Bolivia, 2014. 
H. Piéron, Vocabulario Akal de Psicología, Akal, Madrid, 62, 74, 469-470.

J. Quasten, Musik und Gesang in den Kulten der heidnischen Antike und christlichen Frühzeit, Münster in Westphalia, 1930 (segunda ed. de 1973; trad. inglesa de B. Ramsey, publicada con el título Music and Worship in Pagan and Christian Antiquity, Washington, D. C., 1983)

J.D. Quesada. «¿Un ‘night-club’ frente al Teatro Real?», http://elpais.com/diario/2011/05/18/ madrid/1305717866_850215.html [acceso: 17.05.2015]

Real Academia Española, Diccionario de la lengua española, (ed. n²2), Madrid, 2001.

J. Ratzinger, A new song for the Lord: faith in Christ and liturgy today, (trad. esp.), Nueva York, 1996.

L. Rhodes, «Use of the Hemi-Sync super sleep tape with a preschool-aged child», Hemi-Sync Journal 11 [4] (1996) 4-5.

N. Rodríguez del Real, «Impacto de la espiritualidad en salud mental. Una propuesta de atención comunitaria de salud mental en colaboración con grupos religiosos locales», Psiquiatría universitaria 7 [2] (2011) 205-213.

D. Shannahoff-Khalsa, «Lateralized rhythms of the central and autonomic nervous systems», International Journal of Psychophysiology 11 [3] (1991) 225-251.

L. Smith, R. Webbery J. DeFrain, «Spiritual Well-Being and its relationship to resilience in Young people: a mixed methods case study», Sage Open 3 (2013) doi: 10.1177/2158244013485582

B. Tierno, Aprendiz de sabio, Barcelona, 2005.

P. Vestergaard-Poulsen, M. van Beek, J. Skewes, C.R. Bjarkam, M. Stubberup, J. Bertelsen, y A. Roepstorff., «Long-term meditation in associated with increased grey matter density in the brain stem», Neuroreport: for rapid communication of neuroscience research 20 (2009) 170-174 doi: 10.1097/WNR.0b013e328320012a

J. Vidyarthi, y B.E. Riecke, «Interactively mediating experiences of mindfulness meditation», Int. J. Human-Computer Studies 72 (2014) doi: 10.1016/j.ijhcs.2014.01.006.

R.O. Waldkoetter, G.O. Sanders, «Auditory brain wave stimulation in treating alcoholic depression», Perceptual and Motor Skills 84 [1] (1997) 226.

R. Walsh, y S.L. Shapiro, «The meeting of meditative disciplines and western psychology: A mutually enriching dialogue», American Psychologist 61 (2006) doi: 10.1037/0003066X.61.3.227

P. Westermeyer, «Music and spirituality: Reflections from a Western Christian perspective», Religions 4 (2013) doi: 10.3390/rel4040567

J.M.G. Williams, «Mindfulness and psychological process», Emotion 10 (2010) doi: 10.1037/ a0018360

E.S. Wilson, Preliminary study of the Hemi-Sync sleeps processor, Colorado Association for Psychophysiologic Research, 1990.

B. Wren, Praying Twice: The Words and Music of Congregational Song, Louisville, 2000.

E. Yentzen, «Apuntes sobre la espiritualidad contemporánea, su impacto en la modernidad occidental, y su presencia en Chile», http://dialnet.unirioja.es/servlet/articulo?codigo=2916851 [acceso: 12.11.2014] 